\title{
Minimization of Active Power and Torque Ripple for a Doubly Fed Induction Generator in Medium Voltage Wind Power Systems under Unbalanced Grid Conditions
}

\author{
Yonggyun Park ${ }^{*}$, Daesu Han ${ }^{*}$, Yongsug Suh ${ }^{\dagger}$, and Wooyoung Choi** \\ ${ }^{* \dagger}$ Dept. of Electrical Engineering, Chonbuk National University, Jeonju, Korea \\ ${ }^{* *}$ Div. of Electronic Engineering, Chonbuk National University, Jeonju, Korea
}

\begin{abstract}
This paper investigates control algorithms for a doubly fed induction generator with a back-to-back three-level neutral-point clamped voltage source converter in medium voltage wind power systems under unbalanced grid conditions. Three different control algorithms to compensate for unbalanced conditions have been investigated with respect to four performance factors; fault ride-through capability, instantaneous active power pulsation, harmonic distortions and torque pulsation. The control algorithm having a zero amplitude of torque ripple shows the most cost-effective performance concerning torque pulsation. The least active power pulsation is produced by the control algorithm that nullifies the oscillating component of the instantaneous stator active and reactive powers. A combination of these two control algorithms depending on the operating requirements and the depth of the grid unbalance presents the most optimized performance factors under generalized unbalanced operating conditions leading to high performance DFIG wind turbine systems.
\end{abstract}

Key words: Converter, DFIG, Unbalanced grid conditions, Wind power system

\section{INTRODUCTION}

Wind power systems are one of the fastest growing renewable energy sources. Wind power installations have been increasing both in terms of number and size of individual wind turbine units. Among the various types of wind turbine systems, the Doubly Fed Induction Generator (DFIG) is widely used as a wind generator due to its economic requirement of the power converter in the rotor side. Typically a power converter having $25 \% \sim 30 \%$ of the generator rating is employed in the rotor side of a DFIG to meet the variable speed range of a wind turbine.

Because of the direct connection between the stator and the grid, an unbalanced grid voltage causes unbalanced stator currents. The unbalanced currents generate unequal heating of the stator windings and oscillations of the torque and output power resulting in mechanical stress on the drive train and

Manuscript received Mar. 25, 2013; revised Sep. 5, 2013

Recommended for publication by Associate Editor Dehong Xu.

${ }^{\dagger}$ Corresponding Author: ysuh@jbnu.ac.kr

Tel: +82-270-3381, Fax: +82-270-3381, Chonbuk Nat'l University

*Dept. of Electrical Eng., Chonbuk Nat'1 University, Korea gearbox as well as adverse acoustic noise [1]

The control methods for a Grid Side Converter (GSC) to eliminate input power oscillations at the grid side of the rotor under an unbalanced input supply have been investigated in past few years. Song and Nam [2] derived dual current control schemes regulating the instantaneous active power under unbalanced input voltage conditions in the $d q$-synchronous frame. Stankovic and Lipo [3] introduced cases of generalized unbalanced operating conditions. In [4], Suh and Lipo proposed a method to directly control the instantaneous active power at the poles of a rectifier. The proposed control method in [4] can achieve effective elimination of oscillations under a broad range of unbalanced operating conditions.

The control of the Machine Side Converter (MSC) in DFIG wind power systems with a back-to-back converter to reduce torque pulsation by compensating the rotor current under an unbalanced grid voltage has been studied in [5] and [6]. The active power ripple flowing into the grid and the torque pulsation of the DFIG were reduced by controlling the MSC under unbalanced grid conditions in [7]. Control method to reduce torque pulsation and rotor current harmonics by compensating negative sequence components utilizing either 


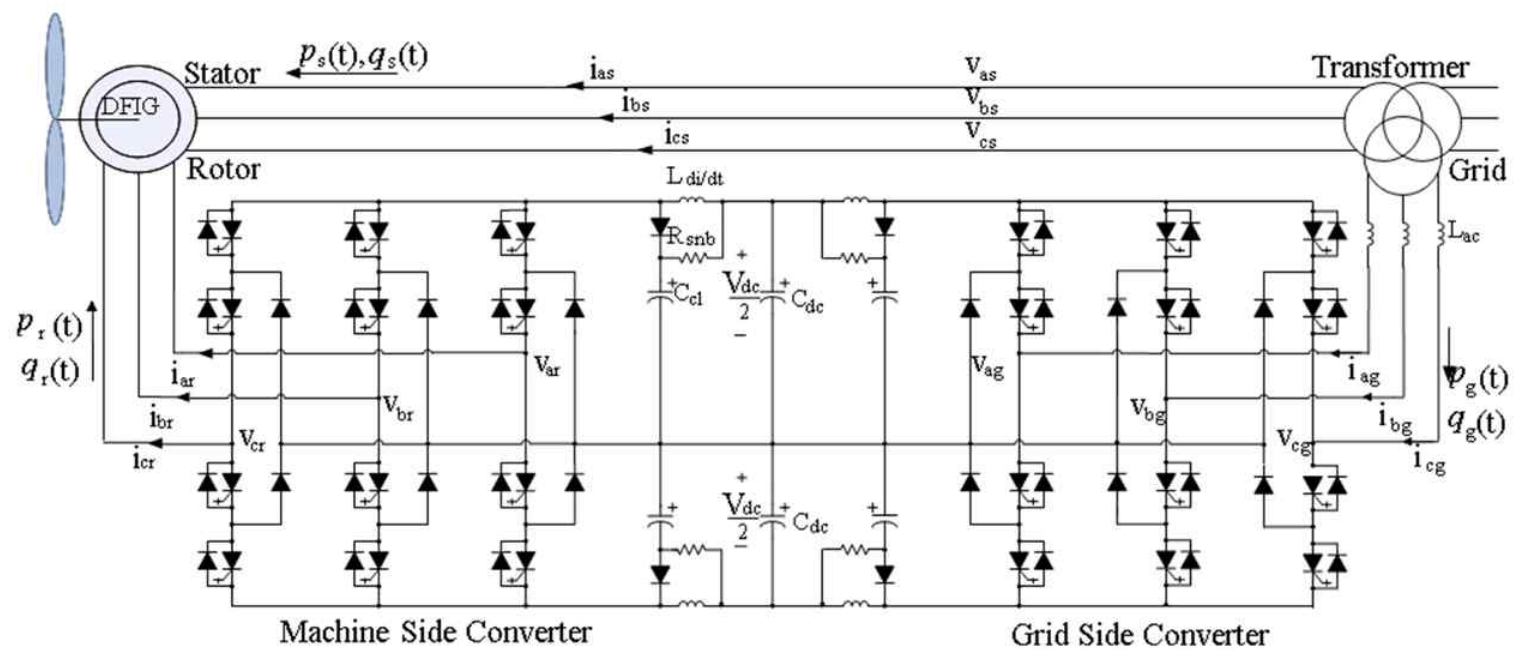

Fig. 1. Overall scheme of DFIG wind turbine system with a back-to-back three-level NPC voltage source converter.

the GSC or MSC was developed in [8]. In [9]-[13], control methods to eliminate pulsations of torque using the MSC and to compensate oscillation of the active and reactive powers using the GSC were presented.

The field of high power drives has been one of the most active areas of research and development for power electronics in last decade. A variety of multilevel voltage source converter topologies for high power drives have been introduced to the market [14]. Efficiency and system operational reliability are considered to be the key performance factors for large drives [15]. In particular, overall system efficiency is a significant factor because of the growing concern in terms of energy savings and cost. The unbalance compensating control algorithms for wind turbine systems in the MW range should take the key performance factors and peculiar features of high power drive systems, such as relatively low control bandwidth, into consideration. Baier et al. [16] investigated the effect of input unbalance in the case of the multicell topology. However, to date very few studies dealing with practical unbalance compensating control algorithms suitable for the high power converter systems of wind turbines can be found in the literature.

In this paper, three different unbalance compensating control algorithms are compared for medium-voltage wind power system using a DFIG equipped with a back-to-back three-level neutral-point clamped voltage source converter. The problems generated by unbalanced grid conditions such as overcurrent of the stator and rotor, active and reactive power ripples, torque pulsation, and degradation of the THD of the line currents are evaluated. Using the control laws addressed in [4] and [17], the key performance factors of fault ride-through capability, instantaneous active power pulsation, harmonic distortions, and torque pulsation are investigated with respect to each control algorithm. A cost-effective and most-optimized control algorithm suitable for the DFIG in medium-voltage wind power systems is proposed in this paper.

\section{DYNAMIC MODEL OF THE DFIG UNDER UNBALANCED CONDITIONS}

\section{A. DFIG Model under Unbalanced Conditions}

Under an unbalanced grid voltage, a DFIG can be effectively modeled by using both the positive and negative sequence components of voltages and currents. The positive and negative sequence components for the voltages of the stator and rotor in the synchronous rotating frame are expressed as follows. In this paper, the direction of the stator/rotor current and stator/rotor power are defined using the motor convention, i.e. positive when flowing into the machine winding from the grid.

$$
\begin{gathered}
V_{d q s}^{p}=R_{s} I_{d q s}^{p}+L_{s}\left(\frac{d}{d t} I_{d q s}^{p}+j \omega I_{d q s}^{p}\right)+L_{m}\left(\frac{d}{d t} I_{d q r}^{p}+j \omega I_{d q r}^{p}\right) \\
V_{d q r}^{p}=R_{r} I_{d q r}^{p}+L_{r}\left(\frac{d}{d t} I_{d q r}^{p}+j\left(\omega-\omega_{r}\right) I_{d q r}^{p}\right) \\
+L_{m}\left(\frac{d}{d t} I_{d q s}^{p}+j\left(\omega-\omega_{r}\right) I_{d q s}^{p}\right) \\
V_{d q s}^{n}=R_{s} I_{d q s}^{n}+L_{s}\left(\frac{d}{d t} I_{d q s}^{n}-j \omega I_{d q s}^{n}\right)+L_{m}\left(\frac{d}{d t} I_{d q r}^{n}-j \omega I_{d q r}^{n}\right) \\
V_{d q r}^{n}=R_{r} I_{d q r}^{n}+L_{r}\left(\frac{d}{d t} I_{d q r}^{n}-j\left(\omega+\omega_{r}\right) I_{d q r}^{n}\right) \\
+L_{m}\left(\frac{d}{d t} I_{d q s}^{n}-j\left(\omega+\omega_{r}\right) I_{d q s}^{n}\right)
\end{gathered}
$$

The subscripts ' $s$ ' and ' $\mathrm{r}$ ' signify the stator and rotor components. The superscript ' $s$ ' indicates the stationary reference frame. The superscripts ' $p$ ' and ' $n$ ' indicate the positive and negative sequence components in the CCW-rotating synchronous reference frame and the $\mathrm{CW}$-rotating synchronous reference frame, respectively. Under the assumptions of zero resistive voltage drops and the steady-state condition, (1) and (3) become:

$$
\begin{gathered}
V_{d q s}^{p}=j \omega L_{s} I_{d q s}^{p}+j \omega L_{m} I_{d q r}^{p} \\
V_{d q s}^{n}=-j \omega L_{s} I_{d q s}^{n}-j \omega L_{m} I_{d q r}^{n}
\end{gathered}
$$




\section{B. Instantaneous Active and Reactive Power at the Stator}

The instantaneous active power of the stator is obtained by taking the real part of the complex power. The instantaneous active power yields the equations of $P_{s o}, P_{s c 2}$, and $P_{s s 2}$ [4].

$$
\begin{aligned}
& S_{s}=\frac{3}{2} V_{d q s}^{s} I_{d q s}^{s^{*}}=\frac{3}{2}\left(e^{j \omega t} V_{d q s}^{p}+e^{-j \omega t} V_{d q s}^{n}\right)\left(e^{j \omega t} I_{d q s}^{p}+e^{-j \omega t} I_{d q s}^{n}\right)^{*} \\
& p_{s}(\mathrm{t})=\operatorname{Re}\left\{S_{s}\right\}=P_{s o}+P_{s c 2} \cos (2 \omega t)+P_{s s 2} \sin (2 \omega t)
\end{aligned}
$$

The instantaneous reactive power can be developed based on a set of voltages lagging the pole voltages by $90^{\circ}$ [4]. A complex quantity, $T_{s}$, referred to as the quadrature complex power, is defined and given in (9).

$$
\begin{aligned}
& T_{s}=\frac{3}{2} V_{d q s}^{s} I_{d q s}^{s^{*}}=\frac{3}{2}\left(-j e^{j \omega t} V_{d q s}^{p}+j e^{-j \omega t} V_{d q s}^{n}\right)\left(e^{j \omega t} I_{d q s}^{p}+e^{-j \omega t} I_{d q s}^{n}\right)^{*} \\
& q_{s}(\mathrm{t})=\operatorname{Re}\left\{T_{s}\right\}=Q_{s o}+Q_{s c 2} \cos (2 \omega t)+Q_{s s 2} \sin (2 \omega t)
\end{aligned}
$$

The active $\left(p_{s}\right)$ and reactive $\left(q_{s}\right)$ powers of the stator are to be controlled by the rotor currents in the DFIG system. Hence, the active and reactive powers of the stator need to be represented by the positive and negative sequential components of the rotor current [12].

\section{Output torque}

The output torque $\left(T_{e m}\right)$ is obtained from the electromagnetic output power, $P_{e m}$. The electromagnetic output power, $P_{e m}$ is directly calculated from the energy conversion term of the total output power $\left(P_{e}\right)$.

$$
\begin{gathered}
P_{e}=-\frac{3}{2} \operatorname{Re}\left\{V_{d q s}^{s} I_{d q s}^{s^{*}}\right\}-\frac{3}{2} \operatorname{Re}\left\{V_{d q r}^{s} I_{d q r}^{s^{*}}\right\} \\
{\left[\begin{array}{c}
P_{e m 0} \\
P_{e m s 2} \\
P_{e m c 2}
\end{array}\right]=\frac{3 L_{m} \omega_{r}}{2 L_{s} \omega}\left[\begin{array}{cccc}
V_{d s}^{p} & V_{q s}^{p} & -V_{d s}^{n} & -V_{q s}^{n} \\
-V_{q s}^{n} & V_{d s}^{n} & -V_{q s}^{p} & V_{d s}^{p} \\
-V_{d s}^{n} & -V_{q s}^{n} & V_{d s}^{p} & V_{q s}^{p}
\end{array}\right]\left[\begin{array}{c}
I_{d r}^{p} \\
I_{q r}^{p} \\
I_{d r}^{n} \\
I_{q r}^{n}
\end{array}\right]}
\end{gathered}
$$

\section{CONTROL AlgORITHMS}

\section{A. Ripple-free Stator Power Control Algorithm (CA1)}

The first control algorithm to be investigated in this paper is the ripple-free stator power control algorithm. This algorithm aims to minimize the ripples of the instantaneous active and reactive powers at the stator. In Section II, the average components of the stator active and reactive powers $\left(P_{s o}\right.$ and $Q_{s o}$ ) along with the ripple components of the instantaneous active power at the stator $\left(P_{s c 2}\right.$ and $\left.P_{s s 2}\right)$ are represented by the sequential components of the stator voltage and rotor current. This description is given in (13) and (14).

Based on (13) and (14), the positive and negative sequential components of the rotor current $\left(I_{d r}^{p}, I_{q r}^{p}, I_{d r}^{n}\right.$, and $\left.I_{q r}^{n}\right)$ can be calculated from four control laws.

$$
\left[\begin{array}{c}
P_{s o} \\
Q_{s o} \\
P_{s s 2} \\
P_{s c 2}
\end{array}\right]=\frac{3}{2}\left[\begin{array}{cccc}
V_{d s}^{p} & V_{q s}^{p} & V_{d s}^{n} & V_{q s}^{n} \\
V_{q s}^{p} & -V_{d s}^{p} & -V_{q s}^{n} & V_{d s}^{n} \\
V_{q s}^{n} & -V_{d s}^{n} & -V_{q s}^{p} & V_{d s}^{p} \\
V_{d s}^{n} & V_{q s}^{n} & V_{d s}^{p} & V_{q s}^{p}
\end{array}\right]\left[\begin{array}{c}
I_{d s}^{p} \\
I_{q s}^{p} \\
I_{d s}^{n} \\
I_{q s}^{n}
\end{array}\right]
$$

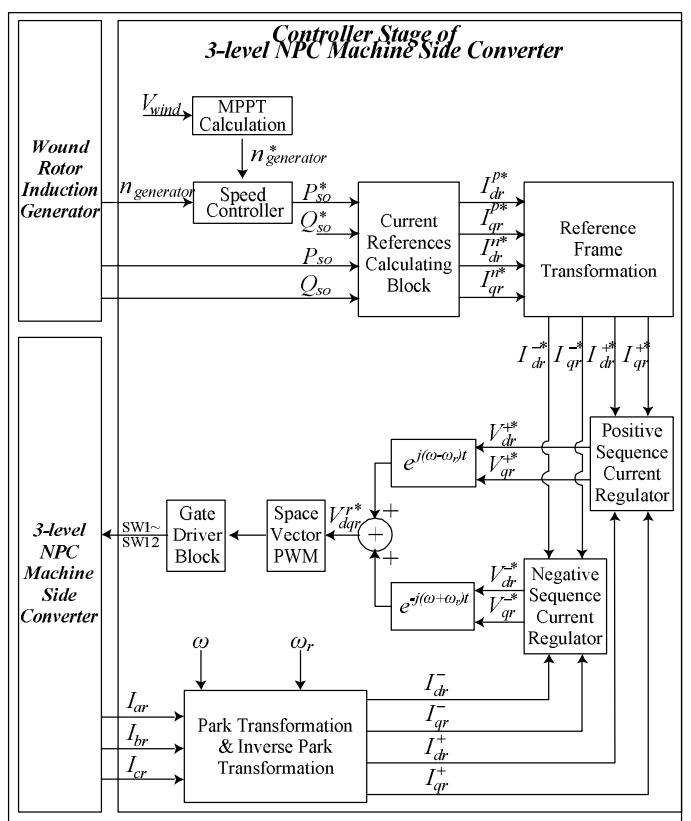

Fig. 2. Control system block diagram of Machine Side Converter.

$$
\left[\begin{array}{c}
I_{d s}^{p} \\
I_{q s}^{p} \\
I_{d s}^{n} \\
I_{q s}^{n}
\end{array}\right]=\frac{1}{\omega L_{s}}\left[\begin{array}{c}
V_{q s}^{p} \\
-V_{d s}^{p} \\
-V_{q s}^{n} \\
V_{d s}^{n}
\end{array}\right] \quad-\frac{L_{m}}{L_{s}}\left[\begin{array}{c}
I_{d r}^{p} \\
I_{q r}^{p} \\
I_{d r}^{n} \\
I_{q r}^{n}
\end{array}\right]
$$

The first control law is about the average active power of the stator as shown in (15).

$$
P_{\text {so }}=P_{\text {output }} \Rightarrow f_{1}\left(I_{d r}^{p}, I_{q r}^{p}, I_{d r}^{n}, I_{q r}^{n}\right)=P_{\text {output }}
$$

The second control law determines the average reactive power of the stator described in (16). The average reactive power $Q_{s o}$ exchanged between the stator and the grid determines the power factor.

$$
Q_{s o}=0 \quad \Rightarrow \quad f_{2}\left(I_{d r}^{p}, I_{q r}^{p}, I_{d r}^{n}, I_{q r}^{n}\right)=0
$$

The third and fourth control laws are achieved by setting both $P_{s c 2}$ and $P_{s s 2}$ to zero thereby nullifying the oscillating components of the instantaneous active power at the stator.

$$
\begin{array}{llll}
P_{s c 2}=0 & \Rightarrow & f_{3}\left(I_{d r}^{p}, I_{q r}^{p}, I_{d r}^{n}, I_{q r}^{n}\right)=0 \\
P_{s s 2}=0 & \Rightarrow & f_{4}\left(I_{d r}^{p}, I_{q r}^{p}, I_{d r}^{n}, I_{q r}^{n}\right)=0
\end{array}
$$

The four rotor current components $\left(I_{d r}^{p}, I_{q r}^{p}, I_{d r}^{n}\right.$, and $\left.I_{q r}^{n}\right)$ are calculated from (15)-(18). The rotor currents in an explicit form are given in the following.

$$
\begin{gathered}
I_{d r}^{p}=-\frac{2 L_{s}}{3 L_{m}} \frac{V_{d s}^{p} P_{s o}}{\left(\left(V_{d s}^{p}\right)^{2}+\left(V_{q s}^{p}\right)^{2}-\left(V_{d s}^{n}\right)^{2}-\left(V_{q s}^{n}\right)^{2}\right)}+\frac{V_{q s}^{p}}{\omega L_{m}} \\
I_{q r}^{p}=-\frac{2 L_{s}}{3 L_{m}} \frac{V_{q s}^{p} P_{s o}}{\left(\left(V_{d s}^{p}\right)^{2}+\left(V_{q s}^{p}\right)^{2}-\left(V_{d s}^{n}\right)^{2}-\left(V_{q s}^{n}\right)^{2}\right)}-\frac{V_{d s}^{p}}{\omega L_{m}} \\
I_{d r}^{n}=\frac{2 L_{s}}{3 L_{m}} \frac{V_{d s}^{n} P_{s o}}{\left(\left(V_{d s}^{p}\right)^{2}+\left(V_{q s}^{p}\right)^{2}-\left(V_{d s}^{n}\right)^{2}-\left(V_{q s}^{n}\right)^{2}\right)}-\frac{V_{q s}^{n}}{\omega L_{m}}
\end{gathered}
$$




$$
I_{q r}^{n}=\frac{2 L_{s}}{3 L_{m}} \frac{V_{q s}^{n} P_{s o}}{\left(\left(V_{d s}^{p}\right)^{2}+\left(V_{q s}^{p}\right)^{2}-\left(V_{d s}^{n}\right)^{2}-\left(V_{q s}^{n}\right)^{2}\right)}+\frac{V_{d s}^{n}}{\omega L_{m}}
$$

The entire control block diagram for the MSC is illustrated in Fig. 2. The current reference calculating block using (19)-(22) to compute the four rotor current components is also employed in Fig. 2. These four rotor current components are used as reference signals in the dual-frame current regulator for the MSC. Therefore, the operation of CA1 using the current control scheme, as shown in Fig. 2, ensures that the rotor current has both positive and negative sequential components in the synchronous rotating frame. As a result, the actual rotor current follows these reference values having two frequency terms; the positive slip frequency $\left(\omega-\omega_{r}\right)$ and the negative slip frequency $\left(\omega+\omega_{r}\right)$.

\section{B. Zero Torque Ripple Control Algorithm (CA2)}

The second control algorithm to be considered in this paper is the zero torque ripple control algorithm (CA2). This control algorithm is designed to minimize the torque ripple at the shaft of a wind turbine. When compared to CA1, CA2 involves the instantaneous electromagnetic output power instead of the stator active power to reduce the torque pulsation under grid unbalance operating conditions.

In Section II, the average component of the electromagnetic output power $\left(P_{e m 0}\right)$ along with the ripple components $\left(P_{e m s} 2\right.$ and $\left.P_{e m c 2}\right)$ are represented by the sequential components of the stator voltage and rotor current as shown in (12). The governing equation of the reactive power is added to (12) resulting in (23).

In a similar manner to $\mathrm{CA} 1$, the positive and negative sequential components of the rotor current $\left(I_{d r}^{p}, I_{q r}^{p}, I_{d r}^{n}\right.$, and $I_{q r}^{n}$ ) can be calculated from four control laws based on (23).

$$
\left[\begin{array}{l}
P_{e m 0} \\
Q_{s o}^{\wedge} \\
P_{e m s 2} \\
P_{e m c 2}
\end{array}\right]=\frac{3 L_{m} \omega_{r}}{2 L_{s} \omega}\left[\begin{array}{cccc}
V_{d s}^{p} & V_{q s}^{p} & -V_{d s}^{n} & -V_{q s}^{n} \\
\frac{\omega}{\omega_{r}} V_{q s}^{p} & -\frac{\omega}{\omega_{r}} V_{d s}^{p} & -\frac{\omega}{\omega_{r}} V_{q s}^{n} \frac{\omega}{\omega_{r}} V_{d s}^{n} \\
-V_{q s}^{n} & V_{d s}^{n} & -V_{q s}^{p} & V_{d s}^{p} \\
-V_{d s}^{n} & -V_{q s}^{n} & V_{d s}^{p} & V_{q s}^{p}
\end{array}\right]\left[\begin{array}{c}
I_{d r}^{p} \\
I_{q r}^{p} \\
I_{d r}^{n} \\
I_{q r}^{n}
\end{array}\right]
$$

The first control law is about the electromagnetic output power as shown in (24).

$$
P_{e m 0}=P_{e m} \quad \Rightarrow \quad f_{1}\left(I_{d r}^{p}, I_{q r}^{p}, I_{d r}^{n}, I_{q r}^{n}\right)=P_{e m}
$$

The second control law is calculated from the average reactive power of the stator described in (25).

$$
\begin{gathered}
\hat{Q_{s o}^{\wedge}}=Q_{s o}+\frac{3}{2 \omega L_{s}}\left(\left(V_{q s}^{p}\right)^{2}+\left(V_{d s}^{p}\right)^{2}+\left(V_{q s}^{n}\right)^{2}+\left(V_{d s}^{n}\right)^{2}\right) \\
\Rightarrow \quad f_{2}\left(I_{d r}^{p}, I_{q r}^{p}, I_{d r}^{n}, I_{q r}^{n}\right)=\hat{Q_{s o}}
\end{gathered}
$$

The third and fourth control laws are achieved by setting both $P_{e m s 2}$ and $P_{e m c 2}$ to zero thereby nullifying the oscillating components of the electromagnetic torque as shown in following.

$$
P_{\text {ems } 2}=0 \quad \Rightarrow \quad f_{3}\left(I_{d r}^{p}, I_{q r}^{p}, I_{d r}^{n}, I_{q r}^{n}\right)=0
$$

$$
P_{\text {emc2 }}=0 \quad \Rightarrow \quad f_{4}\left(I_{d r}^{p}, I_{q r}^{p}, I_{d r}^{n}, I_{q r}^{n}\right)=0
$$

The four rotor current components $\left(I_{d r}^{p}, I_{q r}^{p}, I_{d r}^{n}\right.$, and $\left.I_{q r}^{n}\right)$ are calculated from (24)-(27). The rotor currents in an explicit form are given in the following.

$$
\begin{aligned}
I_{d r}^{p} & =\frac{2 L_{s} \omega}{3 L_{m} \omega_{r}} \frac{V_{d s}^{p} P_{e m 0}}{\left(V_{d s}^{p}\right)^{2}+\left(V_{q s}^{p}\right)^{2}-\left(V_{d s}^{n}\right)^{2}-\left(V_{q s}^{n}\right)^{2}}+\frac{V_{q s}^{p}}{\omega L_{m}} \\
I_{q r}^{p} & =\frac{2 L_{s} \omega}{3 L_{m} \omega_{r}} \frac{V_{q s}^{p} P_{e m 0}}{\left(V_{d s}^{p}\right)^{2}+\left(V_{q s}^{p}\right)^{2}-\left(V_{d s}^{n}\right)^{2}-\left(V_{q s}^{n}\right)^{2}}-\frac{V_{d s}^{p}}{\omega L_{m}} \\
I_{d r}^{n} & =\frac{2 L_{s} \omega}{3 L_{m} \omega_{r}} \frac{V_{d s}^{n} P_{e m 0}}{\left(V_{d s}^{p}\right)^{2}+\left(V_{q s}^{p}\right)^{2}-\left(V_{d s}^{n}\right)^{2}-\left(V_{q s}^{n}\right)^{2}}-\frac{V_{q s}^{n}}{\omega L_{m}} \\
I_{q r}^{n} & =\frac{2 L_{s} \omega}{3 L_{m} \omega_{r}} \frac{V_{q s}^{n} P_{e m 0}}{\left(V_{d s}^{p}\right)^{2}+\left(V_{q s}^{p}\right)^{2}-\left(V_{d s}^{n}\right)^{2}-\left(V_{q s}^{n}\right)^{2}}+\frac{V_{d s}^{n}}{\omega L_{m}}
\end{aligned}
$$

The rotor current components are obtained as (28)-(31). These values are used as reference signals in the dual-frame current regulator of a MSC employing CA2.

\section{Single-frame Control Algorithm (CA3)}

The third control algorithm considered in this paper is the single-frame control algorithm. This algorithm has only one current regulator for the positive sequence components of the rotor currents $\left(I_{d r}^{p}\right.$ and $\left.I_{q r}^{p}\right)$. Therefore, the negative sequential components of the rotor current $\left(I_{d r}^{n}\right.$ and $\left.I_{q r}^{n}\right)$ as well as the stator current $\left(I_{d s}^{n}\right.$ and $I_{q s}^{n}$ ) cannot be actively regulated due to the limitation of the single-frame current regulator. In order to compute the $d$ and $q$-axis positive sequential components of the rotor current $\left(I_{d r}^{p}\right.$ and $\left.I_{q r}^{p}\right)$, two conditions; the average active power $\left(P_{s o}\right)$ and the average reactive power $\left(Q_{s o}\right)$ equations should be satisfied. As a result, the upper two rows in the matrix of (13) hold for CA3.

The three-phase switching modulation functions and the pole voltages of machine side converter $\left(V_{a r}, V_{b r}\right.$, and $\left.V_{c r}\right)$ are set to be balanced in a single-frame controller as shown in (32). This means that the negative sequence components of the rotor current ( $I_{d r}^{n}$ and $I_{q r}^{n}$ ) cannot be regulated resulting in uncontrolled values depending on the depth of the unbalance grid voltages.

$$
V_{d r}^{n}=0, V_{q r}^{n}=0
$$

\section{Simulation Result for Three DIFFERENT CONTROL ALGORITHMS}

The three different control algorithms are compared with respect to four performance factors; FRT capability, active power pulsation, harmonic distortions, and torque pulsation. The simulation is made based on the operating conditions specified in Table I. The parameters have been adopted from a GE 1.5MW turbine [18] and [19].

There are many different types of unbalance operating conditions. Among these, the single-phase under-voltage unbalance condition, i.e. type-B in [20], is the most popular 
type of unbalance during the single-line fault condition in a grid network. In this paper, the three different control algorithms are compared under this type-B single-phase under-voltage unbalance condition. In order to describe the depth of the unbalance of the type-B condition in a quantitative way, a parameter called the Unbalance Factor (UF) is employed throughout this paper. The UF is the ratio of the amplitude of the unbalanced phase voltage $\left(\left|V_{\text {unbal }}\right|\right)$ to the amplitude of the balanced voltage $\left(\left|V_{\text {bal }}\right|\right)$ as shown in (33).

$$
U F=\left|V_{\text {unbal }}\right| /\left|V_{\text {bal }}\right|
$$

In Fig. 3, a typical grid code on a low voltage ride-through is shown. It is required that the wind turbine system remain connected to the grid under the grid fault conditions corresponding to the region above the red line. In order to effectively evaluate the three unbalance control algorithms, two unbalance factors of 0.9 and 0.5 are selected in the simulation verification. The operation under the unbalance factor of 0.9 can be regarded as a steady-state fault condition irrespective of the LVRT, while the unbalance factor of 0.5 falls into the transient LVRT condition as given in Fig. 3.

Under the balanced grid network condition, i.e. $\mathrm{UF}=1$, all three different control algorithms, i.e. CA1, CA2, and CA3, show similar performances as expected. The key operational waveforms under the balanced conditions are described in Fig. 4-7. In Fig. 4, the stator and rotor currents are illustrated. The frequency spectrums of the stator and rotor currents are shown in Fig. 4. The instantaneous stator active and reactive powers are obtained and shown in Fig. 5. The corresponding spectrum of the active and reactive powers are also given in Fig. 5. Figure 6 shows both the mechanical torque from the blade and the electromagnetic torque from the DFIG. The frequency spectrum of the two torque quantities are described in Fig. 6.

Under grid voltages of $90 \%$ and $50 \%$ of the single-phase unbalance, i.e. $\mathrm{UF}=0.9$ and $\mathrm{UF}=0.5$, all three control algorithms are evaluated through simulations. The unbalance conditions of $\mathrm{UF}=0.9$ and $\mathrm{UF}=0.5$ have been assumed to be in the steady-state in order to better analyze the steady-state performance of the control algorithms. The simulation waveforms for $\mathrm{CA} 1$ under $\mathrm{UF}=0.9$ are given in Fig. 8-11. The corresponding simulation waveforms for CA2 and CA3 under $\mathrm{UF}=0.9$ are shown in Fig. 12-15 and Fig. 16-19, respectively. As in the case of the simulation waveforms for the balanced condition, the waveforms of the same circuit variables are presented for each control algorithm for the sake of comparison among the control algorithms. The simulation results under the condition of $\mathrm{UF}=0.5$ are provided in Fig. 20-28. The waveforms of each control algorithm are presented in the same format as in $\mathrm{UF}=0.9$.

The reference values of the stator and rotor current utilized in each control algorithm as well as the grid input voltages are summarized in Table II for the case of UF $=0.9$. Under the balanced grid network, the frequency of the rotor current is equal to the rotor slip frequency, $\omega-\omega_{r}$. However, under
TABLE I

PARAMETERS OF DFIG WIND TURBINE SYSTEM

\begin{tabular}{c|c|c}
\hline \hline Parameter & Symbol & Values \\
\hline \hline Rated power & $P_{m}$ & $1.5 \mathrm{MW}$ \\
\hline Rated voltage(line) & $V_{l}$ & $575 \mathrm{~V}$ \\
\hline DC link voltage & $V_{d c}$ & $1200 \mathrm{~V}$ \\
\hline Frequency & $f$ & $50 \mathrm{~Hz}$ \\
\hline Pole pairs & $Z_{p}$ & 2 \\
\hline DC link capacitance & $C_{d c}$ & $36 \mathrm{mF}$ \\
\hline DC link capacitor energy factor & & $55 \mathrm{~J} / \mathrm{kVA}$ \\
\hline Inertia & $J$ & $25 \mathrm{~kg} \cdot \mathrm{m}^{2}$ \\
\hline Gearbox ratio & $N$ & $1: 75.71$ \\
\hline Stator/rotor turns ratio & $N$ & 1 \\
\hline Stator resistance & $R_{s}$ & $1.4 \mathrm{~m} \Omega$ \\
\hline Rotor resistance & $R_{r}$ & $0.992 \mathrm{~m} \Omega$ \\
\hline Stator leakage inductance & $L_{l s}$ & $89.98 \mu \mathrm{H}$ \\
\hline Rotor leakage inductance & $L_{l r}$ & $82.09 \mu \mathrm{H}$ \\
\hline Magnetizing inductance & $L_{m}$ & $1.53 \mathrm{mH}$ \\
\hline Grid-side filter inductance & $L_{a c}$ & $0.6 \mathrm{mH}$ \\
\hline Rated wind speed & $V_{w \cdot r a t e d}$ & $12 \mathrm{~m} / \mathrm{s}$ \\
\hline Switching frequency & $f_{s w}$ & $10 \mathrm{kHz}$ \\
\hline Damping resistor & $R_{s n b}$ & $0.35 \Omega$ \\
\hline Clamp capacitor & $C_{c l}$ & $20 \mu \mathrm{F}$ \\
\hline di/dt limiting inductor & $L_{d i / d t}$ & $3.5 \mu \mathrm{H}$ \\
\hline P-gain of current regulator & $K_{p i}$ & 0.0003 \\
\hline I-gain of current regulator & $K_{i i}$ & 0.03 \\
\hline & &
\end{tabular}

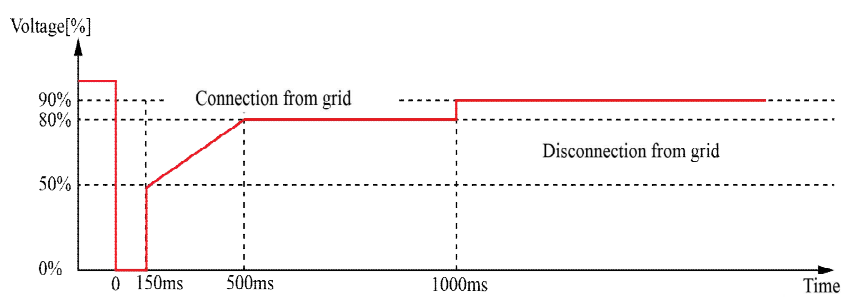

Fig. 3. Typical grid code on low voltage ride-through (KEPCO).

unbalanced grid conditions, the rotor currents have a negative sequence component of $\omega+\omega_{r}$ in addition to a positive sequence component of $\omega-\omega_{r}$. The performance factors for each control algorithm obtained from the simulations are summarized and presented in Table III for the case of $\mathrm{UF}=0.9$. These factors include the ripple size of the stator active and reactive instantaneous powers at $100 \mathrm{~Hz}$, the torque ripple at $100 \mathrm{~Hz}$, the peak values of the rotor currents, and the THD of the stator currents. The reference values of the stator and rotor currents and the values of the performance factors for the case of $\mathrm{UF}=0.5$ are summarized in Table IV and V, respectively.

It is noted from Fig. 9, 13, and 17 that the unbalanced ac grid condition causes the major harmonic component of the instantaneous active and reactive powers at twice the input line frequency, i.e. $100 \mathrm{~Hz}$. As mentioned in Section III, CA1 produces the least amount of harmonic component of the instantaneous active and reactive powers among all three 


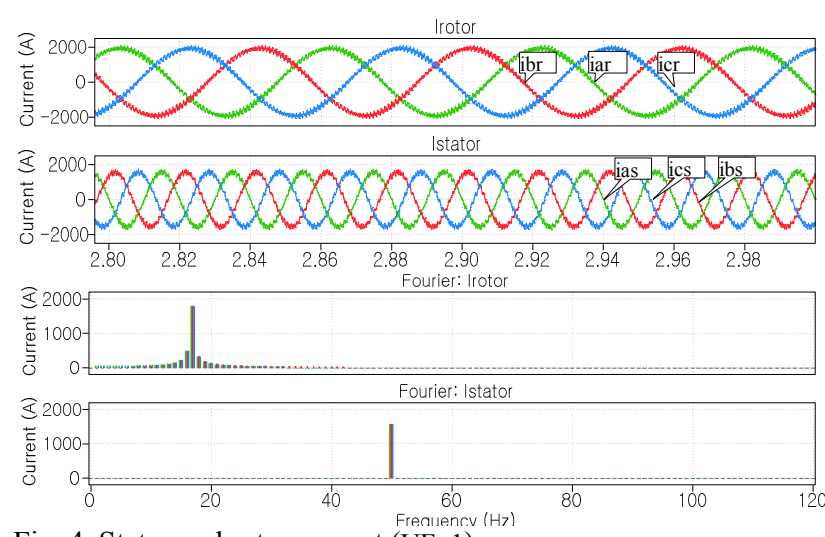

Fig. 4. Stator and rotor current $(\mathrm{UF}=1)$

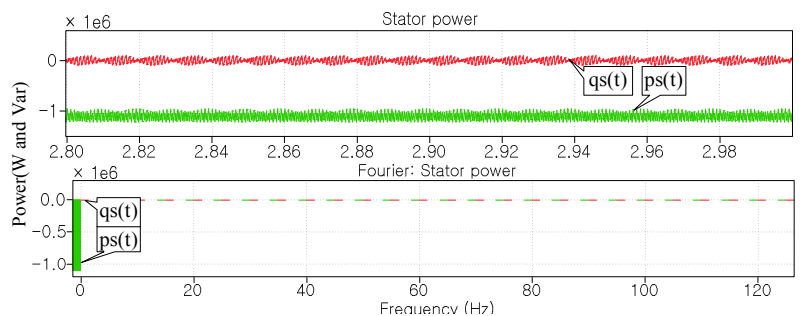

Fig. 5. Instantaneous stator active $\&$ reactive power $(\mathrm{UF}=1)$
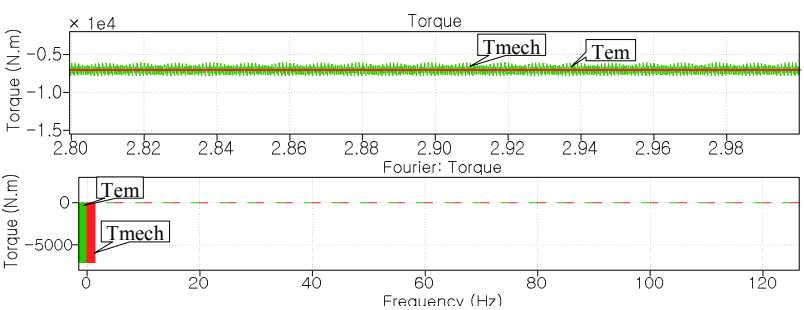

Fig. 6. Blade torque \& electromagnetic torque $(\mathrm{UF}=1)$

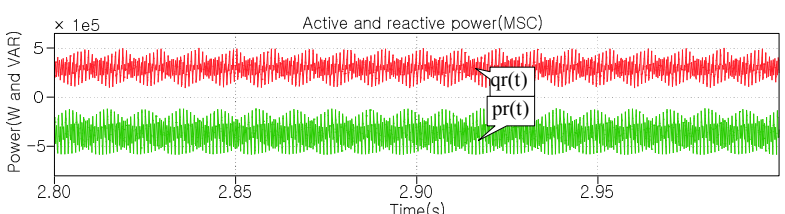

Fig. 7. Instantaneous active $\&$ reactive power of $\operatorname{MSC}(\mathrm{UF}=1)$

control algorithms. It is interesting to note that the ripple sizes of the instantaneous active and reactive powers are the same. This observation is in line with the argument that the instantaneous active and reactive powers have the same ripple size in the time domain [4]. The ripples of the electromagnetic torque for the three different control algorithms are compared in Fig. 10, 14, and 18. Like the instantaneous active and reactive powers, the dominant harmonic component of the torque is produced at twice the input line frequency under unbalanced operating conditions. Among the three different control algorithms, CA2 generates the lowest amount of harmonic component of the electromagnetic torque as mentioned in Section III.

Fault and low voltage ride-through capability is becoming a more and more important performance factor in wind power

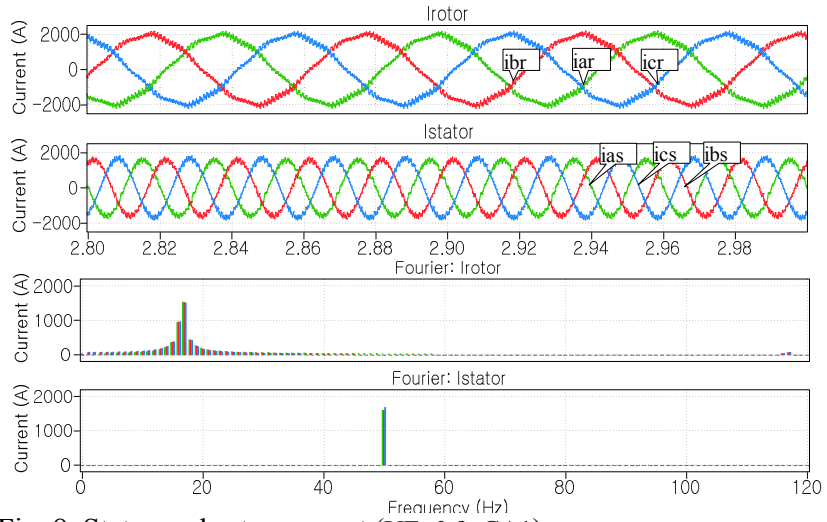

Fig. 8. Stator and rotor current (UF=0.9, CA1)

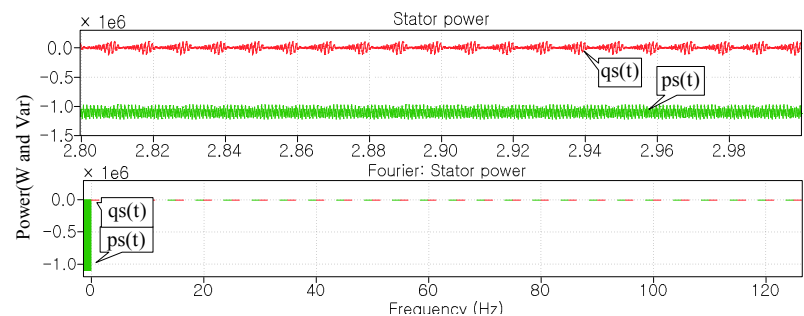

Fig. 9. Instantaneous stator active \& reactive power (UF=0.9, CA1)

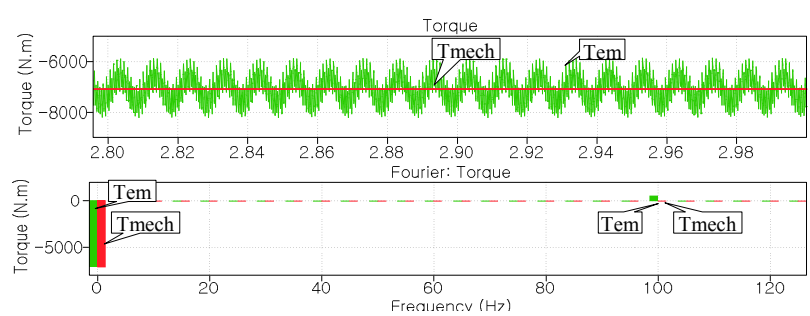

Fig. 10. Blade torque \& electromagnetic torque (UF=0.9, CA1)

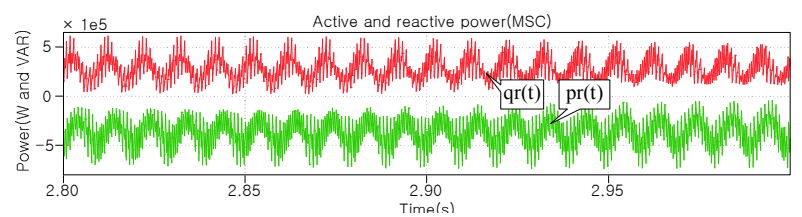

Fig. 11. Instantaneous active \& reactive power of $\mathrm{MSC}(\mathrm{UF}=0.9$, CA1)

systems because of the grid-friendly connection requirements on wind farms. In general, DFIG wind power systems suffer a lot from a relatively weak FRT capability due to the absence of a full-rated power converter between the machine and the grid. A typical grid code requires that during voltage sag conditions, wind turbines should continue their power generation and voltage support without tripping the system. The most common failure or shut-down mechanism of DFIG wind power systems under voltage sag conditions is over current triggered trip. This particular unbalance condition, i.e. voltage sag, induces an unbalanced rotor current resulting in a transient overshoot current. From the simulation results, it can be seen that CA2 generates the smallest value of peak rotor current among the three different control algorithms as shown in Table IV and V. 
TABLE II

Current References for Each Control Algorithm (UF=0.9)

\begin{tabular}{|c|c|c|c|}
\hline \multirow{2}{*}{ Component } & \multirow{2}{*}{ Balanced } & \multicolumn{2}{|c|}{ Unbalanced(UF=0.9) } \\
\hline & & CA 1 & CA 2 \\
\hline$V_{a s}[\mathrm{~V}]$ & $470 \sin (\omega t)$ & $470 \sin (\omega t)$ & $470 \sin (\omega t)$ \\
\hline$V_{b s}[\mathrm{~V}]$ & $470 \sin \left(\omega t+240^{\circ}\right)$ & $470 \sin \left(\omega t+240^{\circ}\right)$ & $470 \sin \left(\omega t+240^{\circ}\right)$ \\
\hline$V_{c s}[\mathrm{~V}]$ & $470 \sin \left(\omega t+120^{\circ}\right)$ & $422 \sin \left(\omega t+120^{\circ}\right)$ & $422 \sin \left(\omega t+120^{\circ}\right)$ \\
\hline$I_{a s}[\mathrm{~A}]$ & $-1562 \sin (\omega t)$ & $-1590 \sin \left(\omega \mathrm{t}-2^{\circ}\right)$ & $-1648 \sin \left(\omega t+3^{\circ}\right)$ \\
\hline$I_{b s}[\mathrm{~A}]$ & $-1562 \sin \left(\omega t+240^{\circ}\right)$ & $-1590 \sin \left(\omega t+242^{\circ}\right)$ & $-1648 \sin \left(\omega t+237^{\circ}\right)$ \\
\hline$I_{c s}[\mathrm{~A}]$ & $-1562 \sin \left(\omega t+120^{\circ}\right)$ & $-1673 \sin \left(\omega t+120^{\circ}\right)$ & $-1563 \sin \left(\omega t+120^{\circ}\right)$ \\
\hline$I_{a r}[\mathrm{~A}]$ & $1922 \sin \left(\left(\omega-\omega_{r}\right) t-31^{\circ}\right)$ & $\begin{array}{c}1956 \sin \left(\left(\omega-\omega_{r}\right) t-29^{\circ}\right) \\
+67 \sin \left(\left(\omega+\omega_{r}\right) t+269^{\circ}\right)\end{array}$ & $\begin{array}{l}1957 \sin \left(\left(\omega-\omega_{r}\right) t-28^{\circ}\right) \\
+68 \sin \left(\left(\omega+\omega_{r}\right) t+31^{\circ}\right)\end{array}$ \\
\hline$I_{b r}[\mathrm{~A}]$ & $1922 \sin \left(\left(\omega-\omega_{r}\right) t+209^{\circ}\right)$ & $\begin{array}{c}1956 \sin \left(\left(\omega-\omega_{r}\right) t+211^{\circ}\right) \\
+67 \sin \left(\left(\omega+\omega_{r}\right) t+29^{\circ}\right)\end{array}$ & $\begin{array}{l}1957 \sin \left(\left(\omega-\omega_{r}\right) t+211^{\circ}\right) \\
+68 \sin \left(\left(\omega+\omega_{r}\right) t+152^{\circ}\right)\end{array}$ \\
\hline$I_{c r}[\mathrm{~A}]$ & $1922 \sin \left(\left(\omega-\omega_{r}\right) t+89^{\circ}\right)$ & $\begin{array}{r}1956 \sin \left(\left(\omega-\omega_{r}\right) t+91^{\circ}\right) \\
+67 \sin \left(\left(\omega+\omega_{r}\right) t+149^{\circ}\right)\end{array}$ & $\begin{array}{l}1957 \sin \left(\left(\omega-\omega_{r}\right) t+91^{\circ}\right) \\
+68 \sin \left(\left(\omega+\omega_{r}\right) t-89^{\circ}\right)\end{array}$ \\
\hline$I_{d r}^{p}[\mathrm{~A}]$ & -979 & -944 & -944 \\
\hline$I_{q r}^{p}[\mathrm{~A}]$ & -1654 & -1713 & -1714 \\
\hline$I_{d r}^{n}[\mathrm{~A}]$ & 0 & -67 & 35 \\
\hline$I_{q r}^{n}[\mathrm{~A}]$ & 0 & -1 & 58 \\
\hline
\end{tabular}
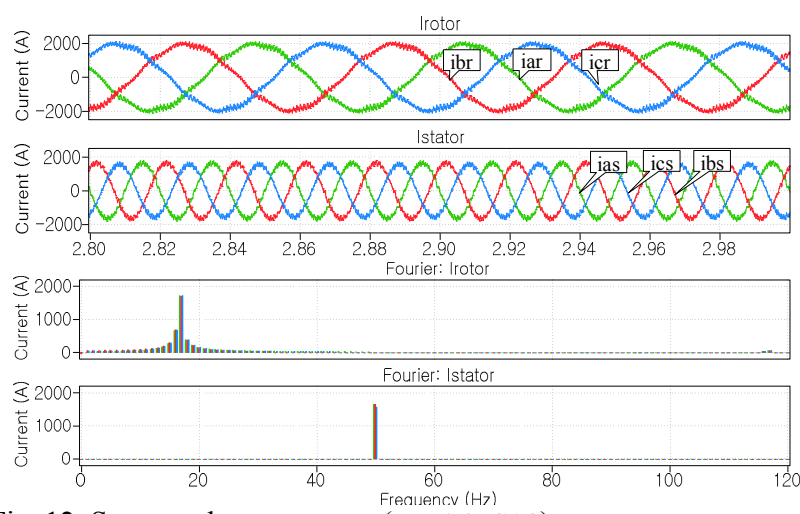

Fig. 12. Stator and rotor current $(\mathrm{UF}=0.9, \mathrm{CA} 2)$

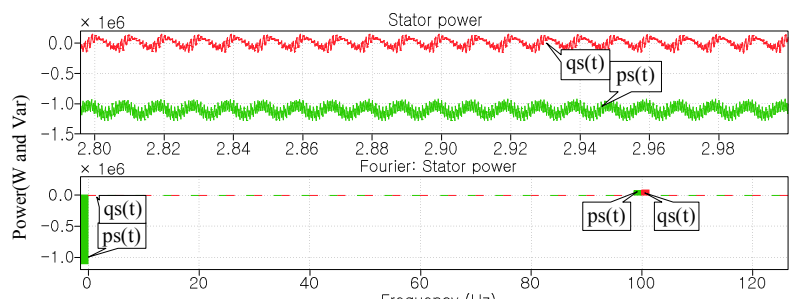

Fig. 13. Instantaneous stator active \& reactive power $(\mathrm{UF}=0.9, \mathrm{CA} 2)$

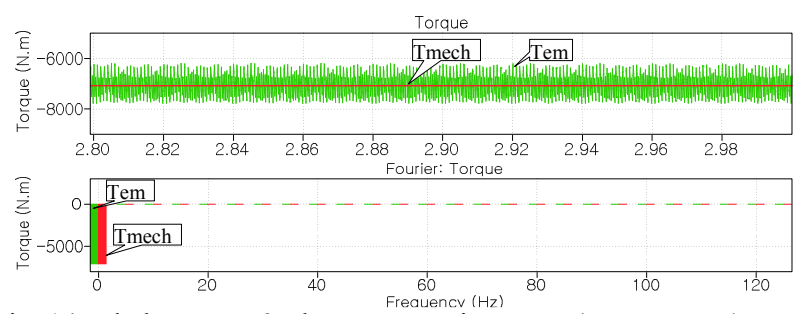

Fig. 14. Blade torque \& electromagnetic torque (UF=0.9, CA2)

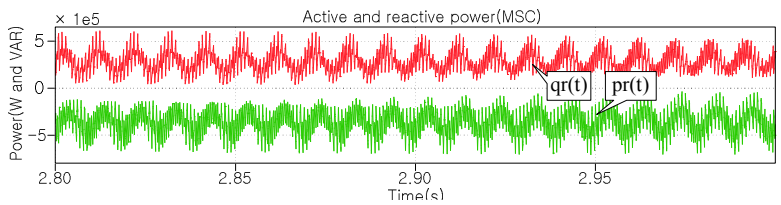

Fig. 15. Instantaneous active \& reactive power of $\mathrm{MSC}(\mathrm{UF}=0.9$, CA2)
TABLE III

PERformance FaCtors FOr EACH CONTROL Algorithm $(\mathrm{UF}=0.9)$

\begin{tabular}{|c|c|c|c|}
\hline \hline Factors & CA 1 & CA 2 & CA 3 \\
\hline \hline $\begin{array}{c}\text { Stator active power } \\
\text { ripple at } 100 \mathrm{~Hz}\end{array}$ & $0 \mathrm{~kW}$ & $75 \mathrm{~kW}$ & $94 \mathrm{~kW}$ \\
\hline $\begin{array}{c}\text { Torque ripple } \\
\text { at } 100 \mathrm{~Hz}\end{array}$ & $487 \mathrm{~N} \cdot \mathrm{m}$ & $6 \mathrm{~N} \cdot \mathrm{m}$ & $973 \mathrm{~N} \cdot \mathrm{m}$ \\
\hline Peak rotor current & $2202 \mathrm{~A}$ & $2123 \mathrm{~A}$ & $2280 \mathrm{~A}$ \\
\hline THD of stator current & $6.2 \%$ & $6.2 \%$ & $8 \%$ \\
\hline
\end{tabular}
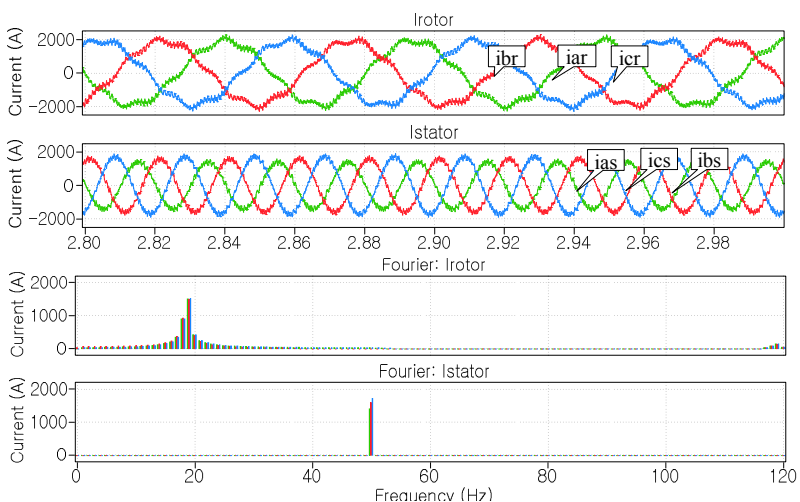

Fig. 16. Stator and rotor current $(\mathrm{UF}=0.9, \mathrm{CA} 3)$

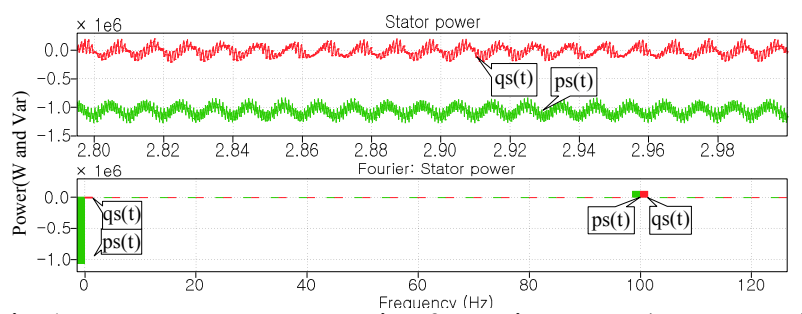

Fig. 17. Instantaneous stator active \& reactive power ( $\mathrm{UF}=0.9, \mathrm{CA} 3)$

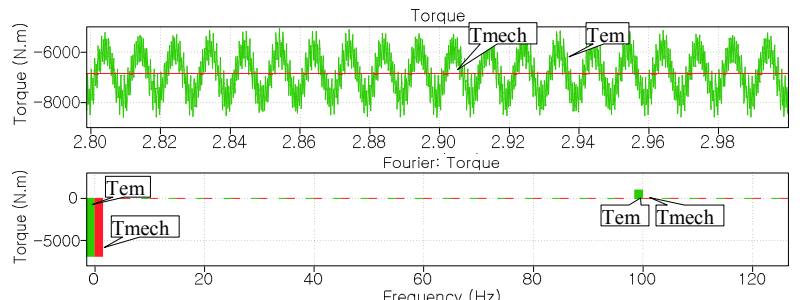

Fig. 18. Blade torque $\&$ electromagnetic torque ( $\mathrm{UF}=0.9, \mathrm{CA} 3)$

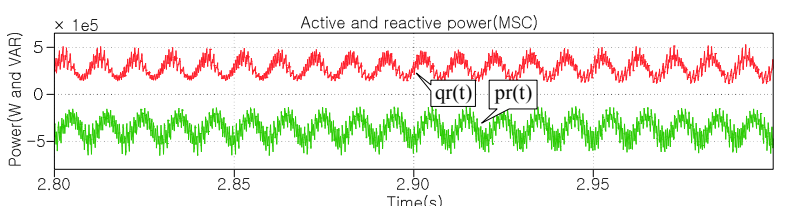

Fig. 19. Instantaneous active \& reactive power of $\mathrm{MSC}(\mathrm{UF}=0.9$, CA3)

In other words, by employing CA2, DFIG systems have better ability to generate the rated power and to maintain voltage support without tripping the MSC in a complete PCS under severe unbalance conditions, i.e. voltage sag.

The instantaneous active $\left(p_{r}\right)$ and reactive powers $\left(q_{r}\right)$ flowing out of the rotor to the machine-side converter have been obtained under the conditions of $U F=1$ and 0.9 for the three different control algorithms. The related waveforms have 


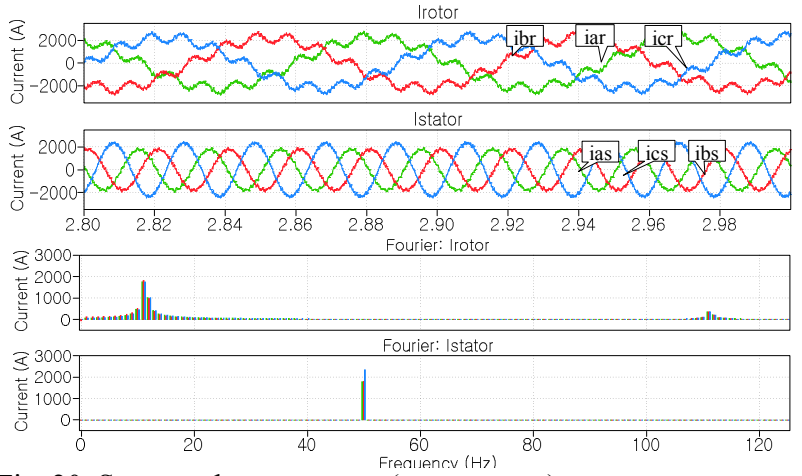

Fig. 20. Stator and rotor current (UF=0.5, CA1)

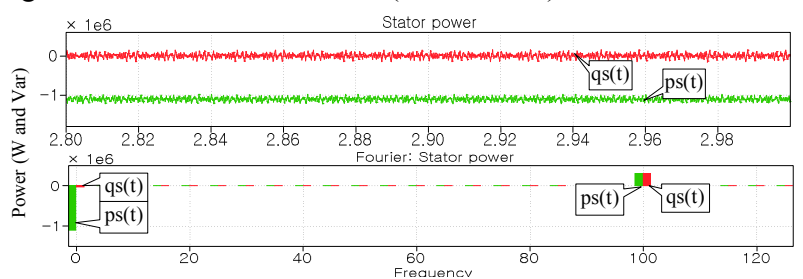

Fig. 21. Instantaneous stator active \& reactive power $(\mathrm{UF}=0.5, \mathrm{CA} 1)$

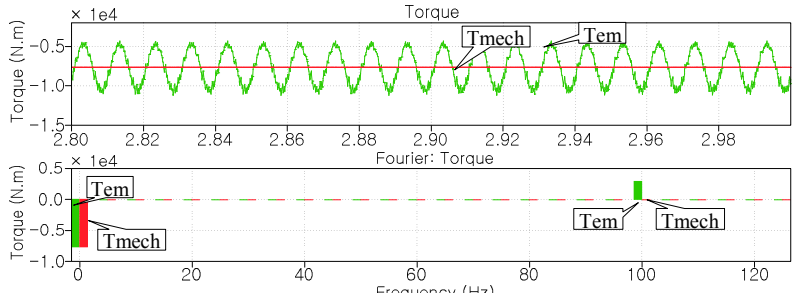

Fig. 22. Blade torque \& electromagnetic torque (UF=0.5, CA1)

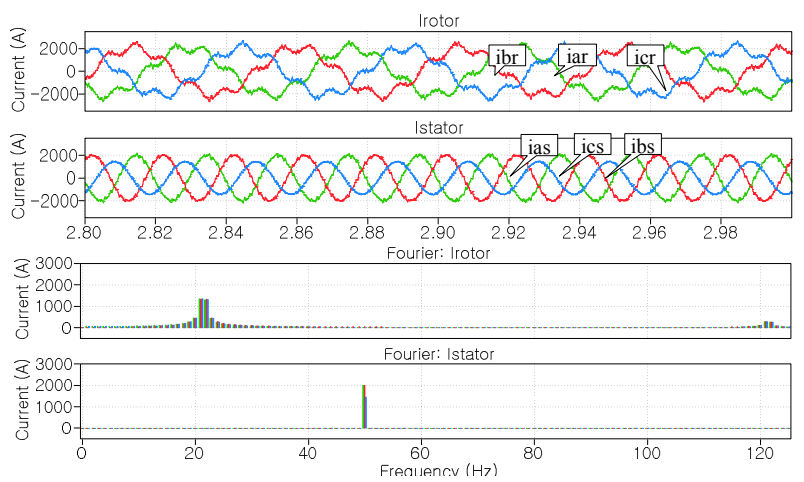

Fig. 23. Stator and rotor current (UF=0.5, $\mathrm{CA} 2)$

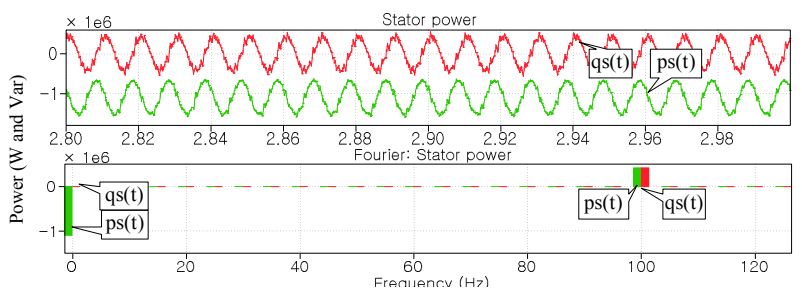

Fig. 24. Instantaneous stator active $\&$ reactive power ( $\mathrm{UF}=0.5, \mathrm{CA} 2)$

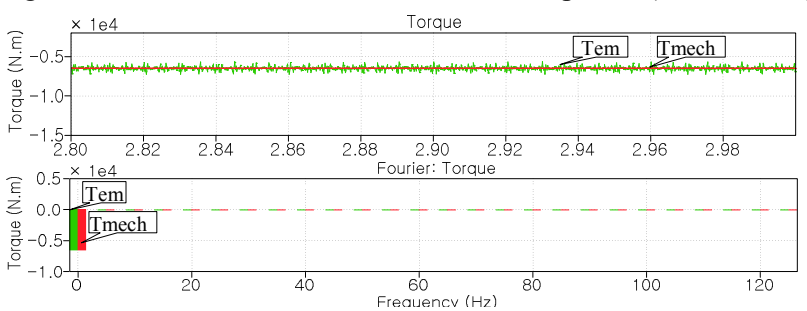

Fig. 25. Blade torque \& electromagnetic torque $(\mathrm{UF}=0.5, \mathrm{CA} 2)$

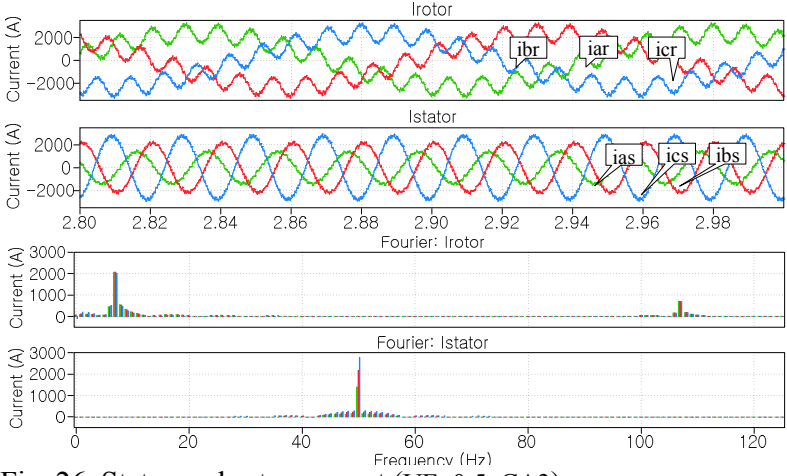

Fig. 26. Stator and rotor current $(\mathrm{UF}=0.5, \mathrm{CA} 3)$

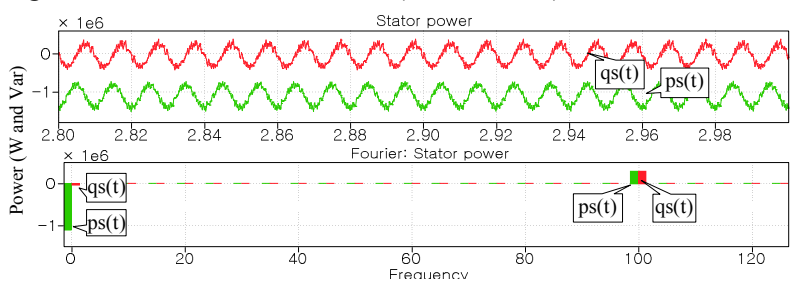

Fig. 27. Instantaneous stator active \& reactive power $(\mathrm{UF}=0.5, \mathrm{CA} 3)$

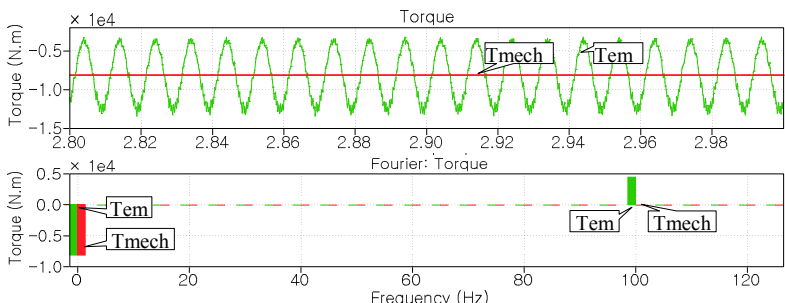

Fig. 28. Blade torque \& electromagnetic torque ( $\mathrm{UF}=0.5, \mathrm{CA} 3)$

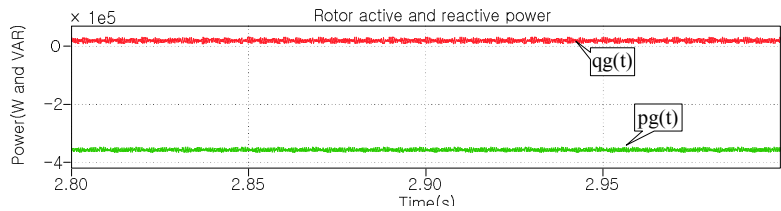

Fig. 29. Instantaneous active \& reactive power of GSC (UF=0.9)

been summarized in Fig. 7, 11, 15, and 19. In every case, the average active power at the rotor side reaches the value of $0.35 \mathrm{MW}$ which is $23 \%$ of the total rated power of the DFIG.

In this paper, the active power and torque of a DFIG are mainly controlled by the machine-side converter in the back-to-back converter system. Instead, the grid-side converter plays a role in regulating the $\mathrm{dc}$ bus and generating reactive power to the grid. In general, the control of this grid-side converter under a grid unbalance can be done as suggested by prior studies [17]. Therefore, the control action on the grid-side converter is not separately treated in this paper. However, in order to understand the complete mechanism of the power flow within the DFIG, the waveforms of the instantaneous active and reactive powers from the grid-side converter to the grid are illustrated in Fig. 29. The average active power is approximately $0.35 \mathrm{MW}$ and the average reactive power is zero, i.e. unity power factor operation. The ripples of both the instantaneous active and reactive powers are maintained to be small as suggested by [17].

Experimental verification of these control algorithms are 
TABLE IV

Current ReFERENCES For EACH CONTROL Algorithm (UF=0.5)

\begin{tabular}{|c|c|c|c|}
\hline \hline \multirow{2}{*}{ Component } & \multirow{2}{*}{ Balanced } & \multicolumn{2}{|c|}{ Unbalanced(UF $=0.5)$} \\
\cline { 3 - 4 } & & CA 1 & CA 2 \\
\hline \hline$V_{a s}[\mathrm{~V}]$ & $470 \sin (\omega t)$ & $470 \sin (\omega t)$ & $470 \sin (\omega t)$ \\
\hline$V_{b s}[\mathrm{~V}]$ & $470 \sin \left(\omega t+240^{\circ}\right)$ & $470 \sin \left(\omega t+240^{\circ}\right)$ & $470 \sin \left(\omega t+240^{\circ}\right)$ \\
\hline$V_{c s}[\mathrm{~V}]$ & $470 \sin \left(\omega t+120^{\circ}\right)$ & $235 \sin \left(\omega t+120^{\circ}\right)$ & $235 \sin \left(\omega t+120^{\circ}\right)$ \\
\hline$I_{a s}[\mathrm{~A}]$ & $-1562 \sin (\omega t)$ & $-1790 \sin \left(\omega t-11^{\circ}\right)$ & $-2003 \sin \left(\omega t+9^{\circ}\right)$ \\
\hline$I_{b s}[\mathrm{~A}]$ & $-1562 \sin \left(\omega t+240^{\circ}\right)$ & $-1790 \sin \left(\omega t+251^{\circ}\right)$ & $-2003 \sin \left(\omega t+231^{\circ}\right)$ \\
\hline$I_{c s}[\mathrm{~A}]$ & $-1562 \sin \left(\omega t+120^{\circ}\right)$ & $-2343 \sin \left(\omega t+120^{\circ}\right)$ & $-1439 \sin \left(\omega t+120^{\circ}\right)$ \\
\hline$I_{a r}[\mathrm{~A}]$ & $1922 \sin \left(\left(\omega-\omega_{r}\right) t-31^{\circ}\right)$ & $\begin{array}{c}2222 \sin \left(\left(\omega-\omega_{r}\right) t-21^{\circ}\right) \\
+444 \sin \left(\left(\omega+\omega_{r}\right) t+261^{\circ}\right)\end{array}$ & $\begin{array}{c}2071 \sin \left(\left(\omega-\omega_{r}\right) t-23^{\circ}\right) \\
+414 \sin \left(\left(\omega+\omega_{r}\right) t+37^{\circ}\right)\end{array}$ \\
\hline$I_{b r}[\mathrm{~A}]$ & $1922 \sin \left(\left(\omega-\omega_{r}\right) t+209^{\circ}\right)$ & $\begin{array}{c}2222 \sin \left(\left(\omega-\omega_{r}\right) t+219^{\circ}\right) \\
+444 \sin \left(\left(\omega+\omega_{r}\right) t+21^{\circ}\right)\end{array}$ & $\begin{array}{c}2071 \sin \left(\left(\omega-\omega_{r}\right) t+217^{\circ}\right) \\
+414 \sin \left(\left(\omega+\omega_{r}\right) t+157^{\circ}\right)\end{array}$ \\
\hline$I_{c r}[\mathrm{~A}]$ & $1922 \sin \left(\left(\omega-\omega_{r}\right) t+89^{\circ}\right)$ & $\begin{array}{c}2222 \sin \left(\left(\omega-\omega_{r}\right) t+99^{\circ}\right) \\
+444 \sin \left(\left(\omega+\omega_{r}\right) t+141^{\circ}\right)\end{array}$ & $\begin{array}{c}2071 \sin \left(\left(\omega-\omega_{r}\right) t+97^{\circ}\right) \\
+414 \sin \left(\left(\omega+\omega_{r}\right) t-83^{\circ}\right)\end{array}$ \\
\hline$I_{d r}^{p}[\mathrm{~A}]$ & -979 & -814 & -814 \\
\hline$I_{q r}^{p}[\mathrm{~A}]$ & -1654 & -2067 & -1904 \\
\hline$I_{d r}^{n}[\mathrm{~A}]$ & 0 & -439 & 248 \\
\hline$I_{q r}^{n}[\mathrm{~A}]$ & 0 & -66 & 331 \\
\hline
\end{tabular}

TABLE V

Performance Factors for Each Control Algorithm $(\mathrm{UF}=0.5)$

\begin{tabular}{|c|c|c|c|}
\hline \hline Factors & CA 1 & CA 2 & CA 3 \\
\hline \hline $\begin{array}{c}\text { Stator active power } \\
\text { ripple at } 100 \mathrm{~Hz}\end{array}$ & $0 \mathrm{~kW}$ & $421 \mathrm{~kW}$ & $295 \mathrm{~kW}$ \\
\hline $\begin{array}{c}\text { Torque ripple } \\
\text { at } 100 \mathrm{~Hz}\end{array}$ & $2918 \mathrm{~N} . \mathrm{m}$ & $7 \mathrm{~N} . \mathrm{m}$ & $4452 \mathrm{~N} . \mathrm{m}$ \\
\hline Peak rotor current & $2826 \mathrm{~A}$ & $2700 \mathrm{~A}$ & $3333 \mathrm{~A}$ \\
\hline THD of stator current & $6.2 \%$ & $5.7 \%$ & $7.4 \%$ \\
\hline
\end{tabular}

under progress and the results will be reported in future publications.

\section{CONCLUSIONS}

This paper investigates unbalance compensating control algorithms for a doubly fed induction wind generator employing a back-to-back three-level NPC voltage source converter. The converter and the DFIG are modeled based on the symmetrical components and the $d q$-synchronous frames under unbalanced grid conditions. Three different control algorithms have been devised based on the instantaneous active and reactive powers of the stator and torque. These algorithms are compared in terms of FRT capability, stator active power ripple, harmonic distortions and torque pulsation. Control algorithm 2, which has the torque ripple set to zero, shows the most optimized and cost-effective performance in terms of torque pulsation. Control algorithm 1, which nullifies the oscillating components of the instantaneous stator active power, surpasses the other two algorithms in terms of the stator active power pulsation. However, as the requirement for the energy factor of the $\mathrm{dc}$ link capacitor becomes reinforced due to the other system specifications in high power drives, the impact on the low ripple of the dc link voltage by employing CA1 becomes less apparent. By combining control algorithm 1 and 2 depending on the depth of the grid unbalance, the four performance factors (FRT capability, stator active power pulsation, harmonic distortions, and torque pulsation) can be improved under the generalized unbalanced grid conditions leading to a high performance DFIG wind turbine system.

\section{ACKNOWLEDGEMENTS}

This work was supported by the National Research Foundation of Korea(NRF) grant funded by the Korea government(MSIP)(No. 2010-0028509)

\section{REFERENCES}

[1] E. Muljadi, T. Batan, D. Yildirim, and C.P. Butterfield, "Understanding the unbalanced-voltage problem in wind turbine generation," in Conference proceedings of IAS 1999 , pp. 1359-1365, Oct. 1999.

[2] H. Song and K. Nam, "Dual current control scheme for pwm converter under unbalanced input voltage conditions," IEEE Trans. Ind. Electron., Vol. 46, No. 5, pp. 953-959, Oct. 1999.

[3] A. Stankovic and T. A. Lipo, "A generalized control method for input-output harmonic elimination for the PWM boost type rectifier under simultaneous unbalanced input voltages and input impedances," in Conference proceedings of PESC, pp. 1309-1314, Jun. 2001.

[4] Y. S. Suh and T. A. Lipo, "Control scheme in hybrid synchronous stationary frame for PWM AC/DC converter under generalized unbalanced operating conditions," IEEE Trans. Ind. Appl., Vol. 42, No. 3, pp. 825-835, May/Jun. 2006.

[5] T. Brekken and N. Mohan, "A novel doubly-fed induction wind generator control scheme for reactive power control and torque pulsation compensation under unbalanced grid voltage conditions," in Conference proceedings of PESC 2003, Vol. 2, pp. 760-764, Jun. 2003.

[6] T. Brekken and N. Mohan, "Control of a doubly fed induction wind generator under unbalanced grid voltage condition," IEEE Trans. Energy Convers., Vol. 22, No.1, pp. 129-135, Mar. 2007.

[7] A. G. Abo-Khalil, D. C. Lee, and J. I. Jang, "Control of back-to-back PWM converters for DFIG wind turbine systems under unbalanced grid voltage," IEEE Industrial Electronics International Symposium, pp. 2637-2642, Jun. 2007.

[8] L. Fan, H. Yin, and R. Kavasseri, "Negative sequence compensation techniques of DFIG-based wind energy systems under unbalanced grid conditions," IEEE Power Electronics and Machines in Wind Applications, pp. 1-6, Jun. 2009.

[9] L. Xu, "Coordinated control of DFIG's rotor and grid side converters during network unbalance," IEEE Trans. Power Electron., Vol. 23, No. 3, pp. 1041-1049, May 2008. 
[10] Y. Wang, L. Xu and B. W. Williams, "Control of DFIG-based wind farms for network unbalance compensation," IEEE Power Electronics Specialists Conference, pp. 113-119, Jun. 2008.

[11] W. Qiao and R. G. Harley, "Improved control of DFIG wind turbines for operation with unbalanced network voltages," IEEE Industry Applications Society Annual Meeting, pp. 1-7, Oct. 2008.

[12] J. Hu and Y. He, "Reinforced control and operation of DFIG-based wind-power-generation system under unbalanced grid voltage conditions," IEEE Trans. Energy Convers., Vol. 24, No. 4, pp. 905-915, Dec. 2009.

[13] L. Xu and Y. Wang, "Dynamic modeling and control of DFIG-based Wind Turbines under unbalanced network conditions," IEEE Trans. Power Syst., Vol. 22, No. 1, pp. 314-323, Feb. 2007.

[14] J. Rodriguez, S. Bernet, B. Wu, J. O. Pontt, and S. Kouro, "Multilevel voltage-source-converter topologies for industrial medium-voltage drives," IEEE Trans. Ind. Electron., Vol. 54, No. 6, pp. 2930-2945, Dec. 2007.

[15] Y. S. Suh, J. Steinke, and P. Steimer, "Efficiency comparison of voltage source and current source drive system for medium voltage applications," IEEE Trans. Ind. Electron., Vol. 54, No. 5, pp. 2521-2531, Oct. 2007.

[16] C. R. Baier, J. I. Guzman, J. R. Espinoza, M. A. Perez, and J. R. Rodriguez, "Performance evaluation of a multicell topology implemented with single-phase nonregenerative cells under unbalanced supply voltages," IEEE Trans. Ind. Electron., Vol. 54, No. 6, pp. 2969-2978, Dec. 2007.

[17] Y. S. Suh, Y. R. Go, and D. H. Rho,"A comparative study on control algorithm for active front-end rectifier of large motor drives under unbalance Input," IEEE Trans. Ind. Appl., Vol. 47, No. 3, pp. 1419-1431, May/June 2011.

[18] J. Schönberger, "Modeling a DFIG wind turbine system using Plecs," Application note of Plexim GmbH, December 2008.

[19] N. Miller, W. Price, and J. Sanchez-Gasca, "Dynamic modeling of GE 1.5 and 3.6 MW wind turbine generators," Technical Report, GE Power Systems Energy Consulting, 2003.

[20] M. Bollen, "Characterisation of voltage sags experienced by three-phase adjustable-speed drives," IEEE Trans. Power Del., Vol. 12, No. 4, pp. 1666-1671, Oct. 1997.

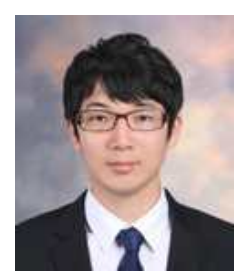

drive systems.

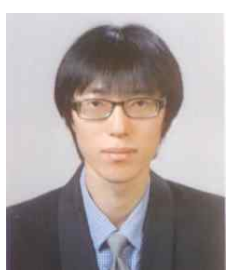

Daesu Han was born in Korea, in 1987. He received his B.S. in Electrical Engineering from Chonbuk National University, Jeonju, Korea, in 2013, where he is currently working toward his M.S. in Electrical Engineering. His current research interests include the power conversion systems of high power for renewable energy sources and medium electric drive systems.

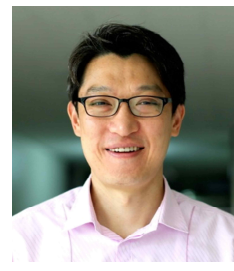

Yongsug Suh was born in Seoul, Korea. He received his B.S. and M.S. in Electrical Engineering from Yonsei University, Seoul, Korea, in 1991 and 1993, respectively, and his Ph.D. in Electrical Engineering from the University of Wisconsin, Madison, WI, USA, in 2004. From 1993 to 1998, he was an Application Engineer in the Power Semiconductor Division of Samsung Electronics Co. From 2004 to 2008, he was a Senior Engineer in the Power Electronics and Medium Voltage Drives Division of ABB, Turgi, Switzerland. Since 2008, he has been with the Department of Electrical Engineering, Chonbuk National University, Jeonju, Korea, where he is currently an Associate Professor. His current research interests include the power conversion systems of high power for renewable energy sources and medium voltage electric drive systems.

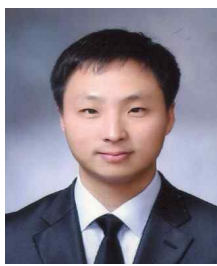

Wooyoung Choi was born in Gwang-ju, South-Korea, in 1979. He received B.S. degree in electrical engineering from Chonnam National University in 2004 and $\mathrm{Ph} . \mathrm{D}$. degree in electronic and electrical engineering from Pohang University of Science and Technology (POSTECH), South-Korea, in 2009. Since 2010, he has been at the division of electronic engineering at Chonbuk National University, now working as an assistant professor. His research interests are power electronics and control for high-efficiency switching power converter designs. 